\title{
Electric Vehicles On-Board Battery Charger for the Future Smart Grids
}

\author{
Vítor Monteiro $^{1}$, João C. Ferreira ${ }^{1}$, \\ Andrés A. Nogueiras Meléndez ${ }^{2}$, and João L. Afonso ${ }^{1}$ \\ ${ }^{1}$ Centro Algoritmi - University of Minho - Guimarães, Portugal \\ ${ }^{2}$ Departamento de Tecnología Electrónica, University of Vigo - Vigo, Spain \\ \{vitor.monteiro, joao.ferreira, joao.1.afonso\} @algoritmi.uminho.pt, \\ aaugusto@uvigo.es
}

\begin{abstract}
The recent and massive investments in Electric Vehicles (EVs) reveal a change of paradigm in the transports sector and the proliferation of EVs will contribute to an effective reduction in the emissions of greenhouse gases. Nevertheless, for the electrical power grids EVs will be extra loads, which will require the demand energy to charge their batteries. With the advent of the Smart Grids, besides the usual battery charging mode (Grid-to-Vehicle - G2V), where the batteries receives energy from the power grid, arises a new concept for the users of EVs and for the power grid market, denominated as Vehicle-to-Grid (V2G).In the V2G operation mode, EVs return to the power grid part of the energy stored in their batteries. The V2G concept requires the use of battery chargers for the EVs with bidirectional power flow capability and bidirectional communication with the Smart Grids through Information and Communication Technology (ICT) applications. It is important to highlight that the proliferation of EVs and the impact of their battery chargers on the power grid quality is a matter of concern, since conventional chargers present current harmonics and power factor problems. In this paper it is presented the preliminary studies resulting from a $\mathrm{PhD}$ work about a bidirectional battery charger for EVs, which was designed to operate in collaboration with the power grid as G2V and V2G through an ICT application. In this way, it is expectable to contribute to the technological innovation of the electric mobility in Smart Grids. To assess the behavior of the proposed battery charger under different scenarios of operation, a prototype has been developed, and some simulation and experimental results of the battery charger are presented.
\end{abstract}

Keywords: Battery Charger, Communication System, Electric Vehicles, Smart Grids, Grid-to-Vehicle (G2V), Vehicle-to-Grid (V2G).

\section{Introduction}

The upcoming reality of Smart Grids and energy markets will raise a diversity of advantages to the end-user. However, it will require several technologic developments aiming the interaction of the users as active players. The recent increase in the utilization of Electric Vehicles (EVs) with different architectures represents a real contribution to a 
new transports paradigm, a gain for independence of the cost of the oil, and also an effective fight against the climatic changes. Effectively, the EVs are seen as one of the most promising means in order to improve the sustainability of the transportation and energy sectors in near-term [1][2].

The EVs in conjunction with Information and Communication Technology (ICT) applications will play an important role to achieve a sustainable balance between production and consumption, and increase the power quality and the reliability of the power grids. The future Smart Grids are the consequence of this new paradigm for the power grids. Smart Grids are not characterized as a particular technology or device, but rather as a vision of a distributed electrical system, supported by reference technologies, as example, the aforementioned ICT, Advanced Metering Infrastructures (AMI), Energy Storage Systems (ESS), Micro Generation (MG), and Power Electronics Systems (PES).Thereby, the actual power grids will be transformed on a coordinated, collaborative [3], and automatic infrastructure [4][5][6].

Nowadays, with the recent bet in EVs around the world, the actual electrical power grids are facing new challenges, forcing to a wide efforts of investigation in different directions [7], mainly taking into account their integration [8][9][10]. Consequently, a considerable amount of energy is stored in the batteries of these vehicles. Thus, besides the charging process (Grid-to-Vehicle - G2V), the energy stored in EVs' batteries may be suitable for providing regulation services, spinning reserves and peak power demand. This interactivity between the vehicles and the power grid is expected to be one of the key technologies in the future of the Smart Grids, denominated Vehicle-to-Grid (V2G) [11][12]. Fig. 1shows a draft of a scenario for a Smart Grid, where the integration of EVs represents the core of the context for this paper.

Power Flow and Information and Communication Technology (ICT) in Smart Grids

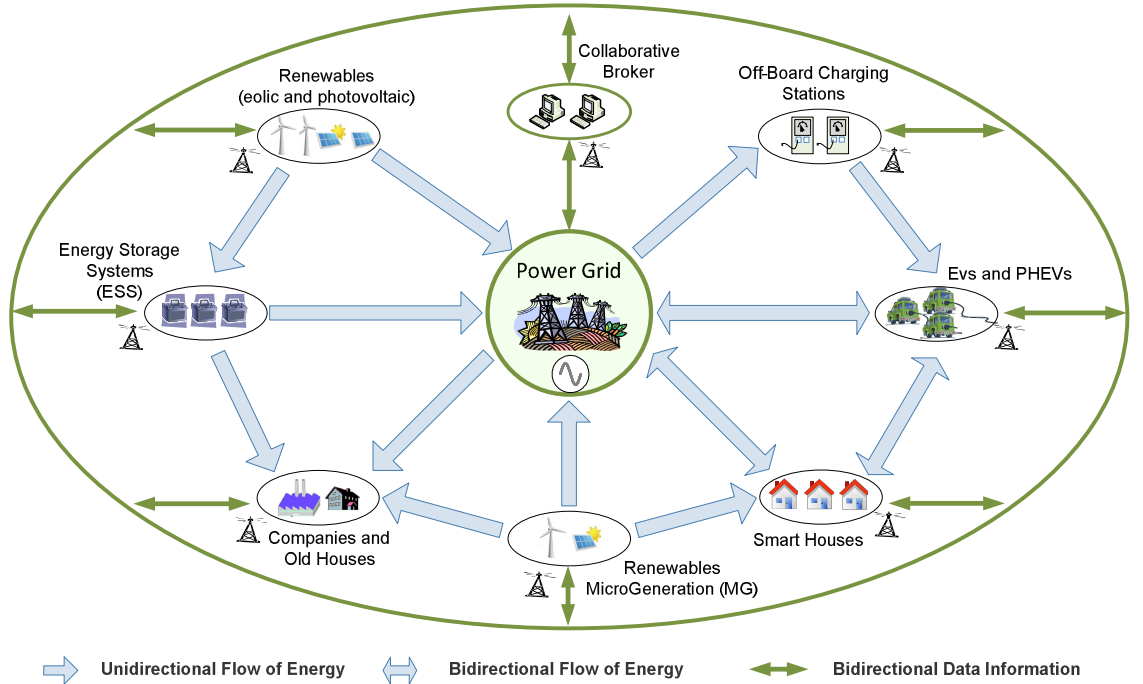

Fig. 1. Scenario for a Smart Grid, where the integration of EVs with bidirectional power flow and communication capabilities represents the core of the context for this paper 
This paper results from a $\mathrm{PhD}$ work that is yet in the first year, and presents a bidirectional battery charger for EVs based on PES with ICT capabilities. This equipment allows mitigate problems associated with power quality (as distorted current consumption and low power factor), enables the operation of EVs as local ESS, and represents an important contribute to the technological innovation, and to the efficiency and reliability of the electric mobility in Smart Grids.

\section{Contribution to Internet of Things}

The Functional Areas in Smart Grids represents all the systems related with the production, transmission and distribution [13][14], and considering Advanced Metering Infrastructure (AMI) and ICT [15][16]. In the electric mobility it is important provide the EVs with ICT systems in order to establish a bidirectional flux of information to ensure that the batteries are charged when the electricity is cheapest and the impact on the grid is smallest. With a coordinated charging process of EVs the energy losses in the distribution system are minimized [17]. To reach this goal, the batteries charging process needs assistance of an intelligent process in order to find the periods with cheaper prices to charge the batteries, to identify the available charging slots in public and private areas, and to provide other useful information to the drivers, as their historic use [18][19]. This theme, including supervision, control and communication applications, will be the final topic that will be addressed in the $\mathrm{PhD}$ work. The main goal is establish a bidirectional flux of information between the EVs and the power grids aiming to define strategies of cooperation to the G2V and V2G modes of operation [20].

In order to contribute to the technological innovation of the electric mobility in Smart Grids, the bidirectional battery charger for EVs presented in this paper was designed to operate in collaboration with the power grid as G2V and V2G through an ICT application [21]. This way, it will be possible exchange information through the internet, contributing to strengthening the Internet of Things and the impact of the electric mobility in the Smart Grids. As aforementioned, besides the bidirectional flow of active power, through the power factor control, it is also possible control the reactive power in accordance with the capabilities of the battery charger [22]. In Fig.2 is shown the integration of EVs in the power grid considering the active and reactive bidirectional power flow of the presented battery charger.

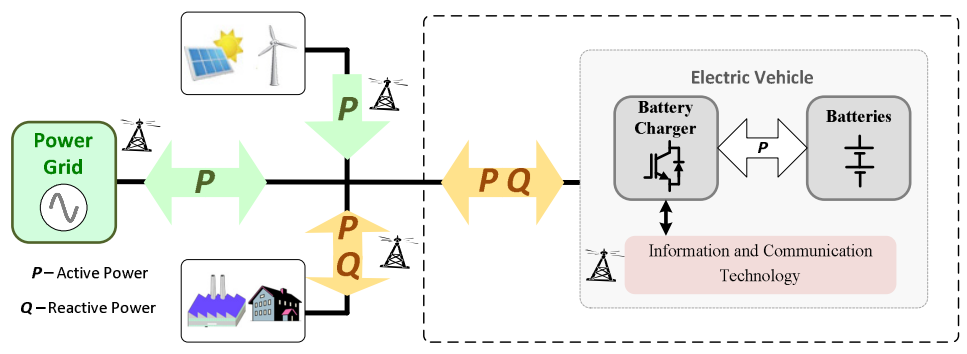

Fig. 2. Smart Grid considering the integration of EVs with bidirectional power flow 


\section{On-Board Battery Charger}

Electric Vehicles are becoming a part of the electric power grid and consequently the battery chargers of these vehicles should have the ability to avoid power quality problems [23][24]. Even more, the EVs power stages can also assume, if needed, the role of the active power quality filters. The battery charger presented in this paper is a device that is composed by two power electronics converters used to adapt the AC electrical energy into DC (AC-DC converter) and to control the output voltage or currents levels (DC-DC converter). To contribute to the power quality in the future Smart Grids, the battery chargers should consume sinusoidal current with controlled power factor. In Fig. 3 is presented the schematic of the first prototype of battery charger developed during the $\mathrm{PhD}$ work.

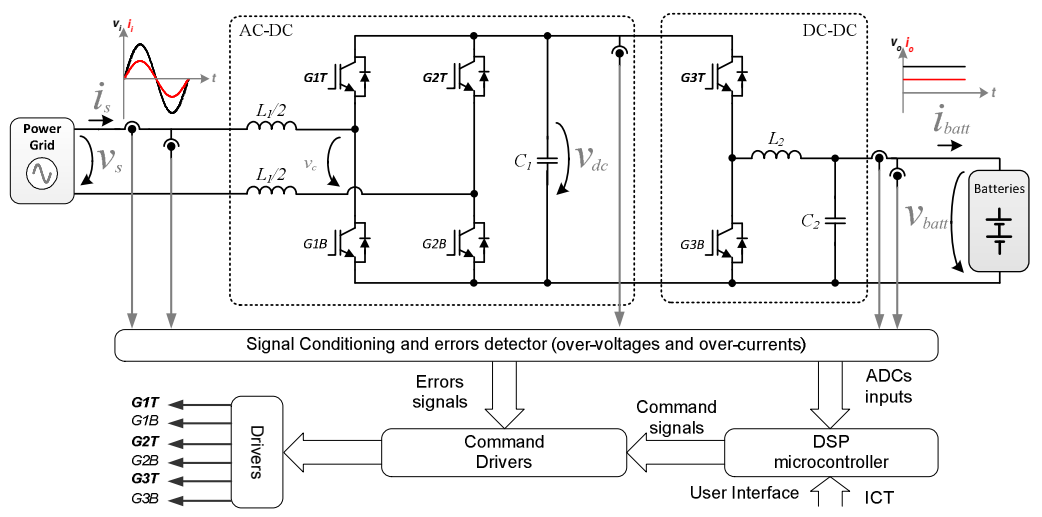

Fig. 3. Schematic of the presented bidirectional power converter

\subsection{Modes of Operation}

In an early stage, in order to analyses the operation of the converters in both modes of operation was developed a simulation model using the simulation tool PSIM, and were realized different computer simulations. In Fig.4 are shown some simulations results obtained during the operation of the bidirectional power converters.

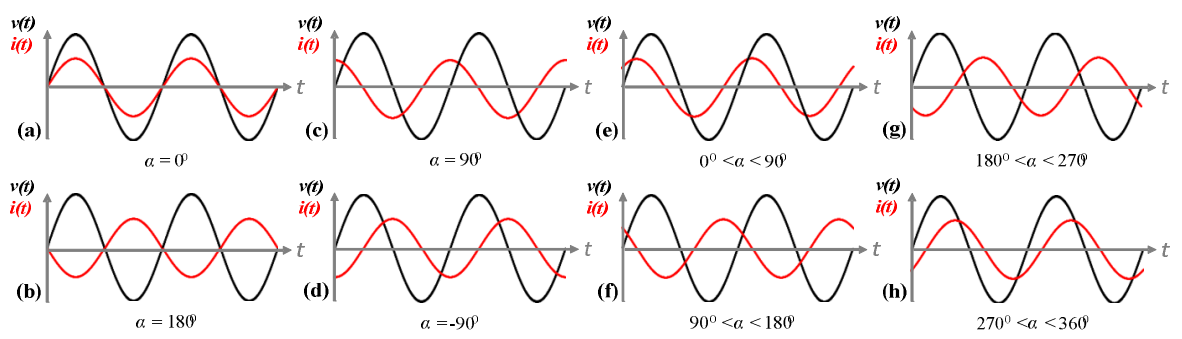

Fig. 4. Summary of some simulation results considering the voltage and the current in the electrical power grid and adjusting the reactive power 


\subsection{Digital Control System}

In a first stage of the $\mathrm{PhD}$ work, in this prototype, the operation of the battery charger occur in accordance with the orders given, according to the demands of the user of the $\mathrm{EV}$, which define when it works as $\mathrm{G} 2 \mathrm{~V}$ and $\mathrm{V} 2 \mathrm{G}$, and the value of reactive power to be produced. The communication with the power grid through an ICT application, instead the user, will be developed along the PhD work where this paper is encompassed. In Fig.5are presented the control algorithms for the AC-DC and DC-DC converters.

(a)

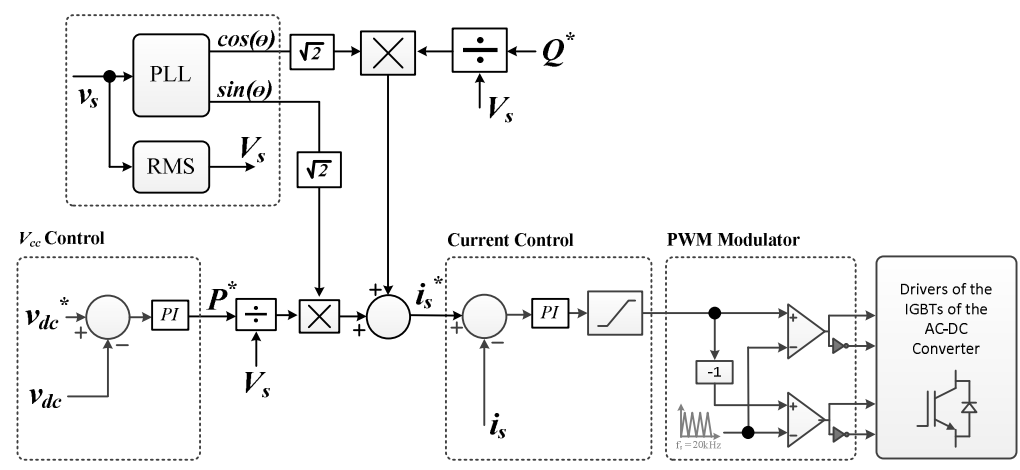

(b)

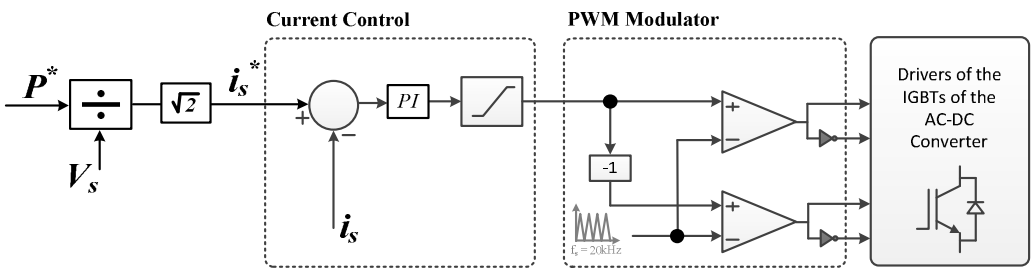

(c)

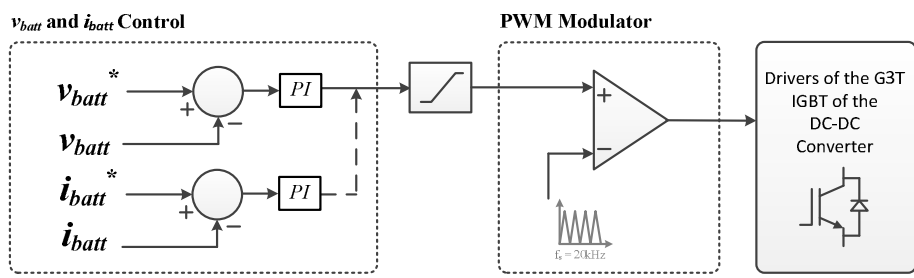

(d)

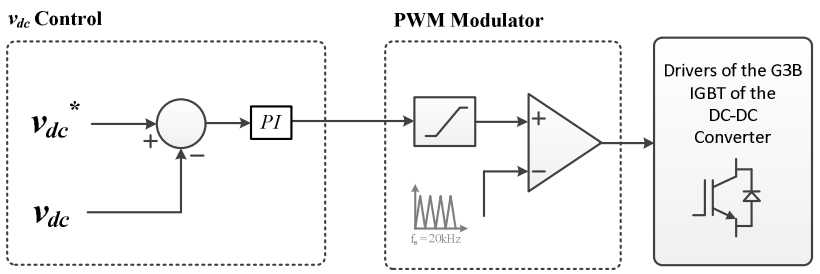

Fig. 5. Control algorithms: AC-DC converter operating as G2V (a) and V2G (b); DC-DC converter operating as G2V (c) and V2G (d) 


\section{Experimental Results}

In order to assess the operation of the on-board battery charger under different modes of operation was developed the prototype presented in Fig.6, aiming to be integrated in an EV with Absorbed Glass Mat batteries with nominal voltage $96 \mathrm{~V}$ and nominal capacity 33 Ah. Preliminary experimental results are shown in Fig.7.
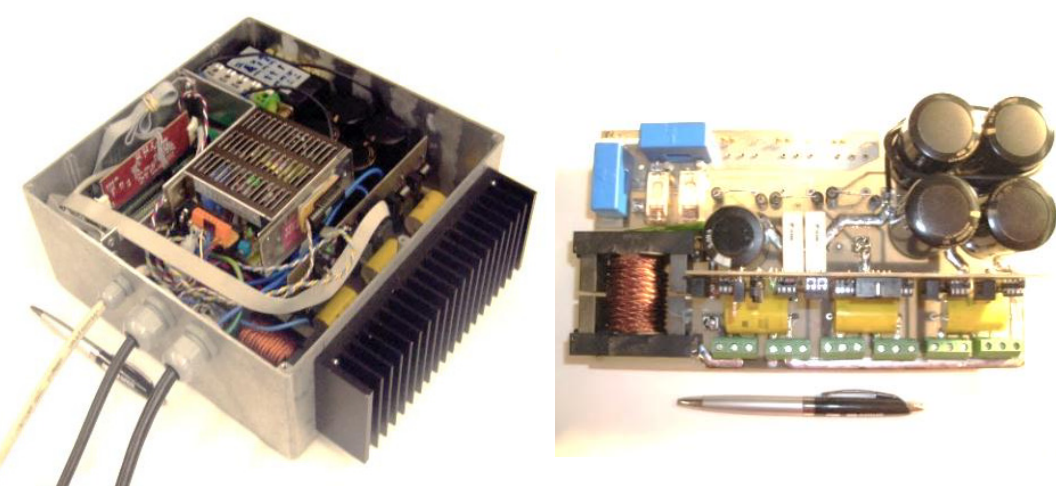

Fig. 6. On-board battery charger prototype developed to operate as G2V and V2G controlled through an ICT application, to be implemented in an Electric Vehicle

(a)

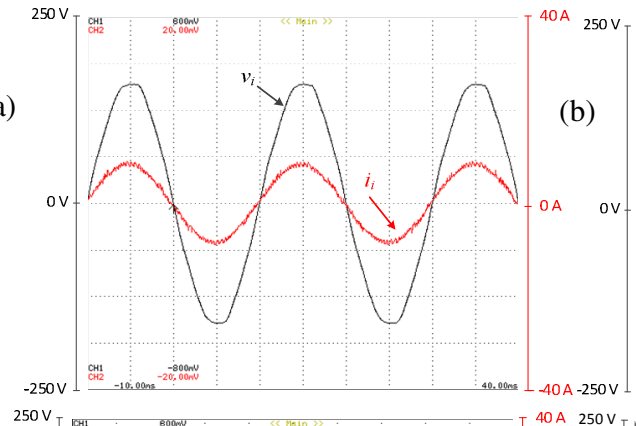

(c)

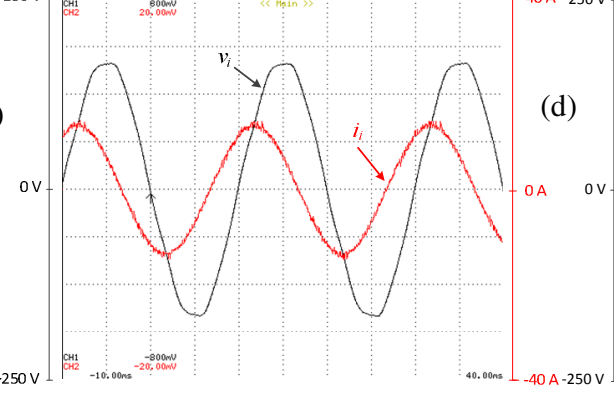

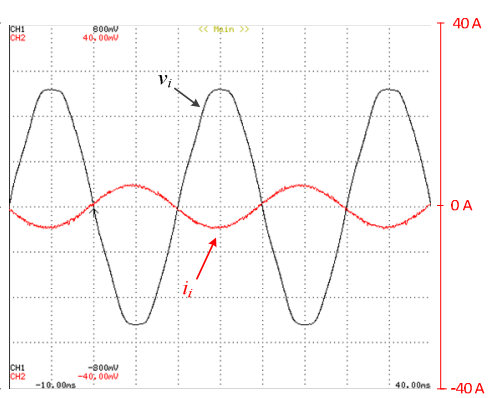

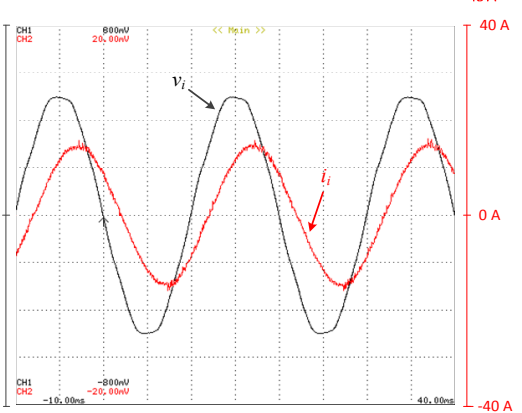

Fig. 7. Experimental results with controlling of the active and reactive power: (a) G2V mode with unitary power factor; (b) V2G mode; (c) G2V mode with capacitive power factor; (d) G2V mode with inductive power factor 


\section{Conclusions and Further Work}

In this paper was presented an on-board battery charger for Electric Vehicles (EVs) aiming their integration in Smart Grids. This battery charger allows the interaction with the electrical power grid to charge the batteries (Grid-to-Vehicle - G2V mode),or to deliver part of the stored energy in the batteries back to the power grid (Vehicle-toGrid - V2G mode). The modes of operation and the reactive power control are performed considering the user interface of the EVs. However, in the final of the PhD work where this paper is encompassed, the goal is to control the on-board battery charger of the EV through an ICT application aiming to allow the communication with a collaborative broker of the electrical power grid.

In a first stage, the behavior of the bidirectional power converter was evaluated under different scenarios through computer simulations. Then the behavior of the bidirectional power converter was evaluated with a prototype, which was developed aiming to reduce its volume and weight, in order to be integrated in an Electric Vehicle with Absorbed Glass Mat (AGM) batteries. In this paper were presented the simulations and experimental results obtained.

Acknowledgments. This work is financed by FEDER Funds, through the Operational Programme for Competitiveness Factors - COMPETE, and by National Funds through FCT - Foundation for Science and Technology of Portugal, under the projects: FCOMP-01-0124-FEDER-022674 and PTDC/EEA-EEL/104569/2008.

\section{References}

1. Bradley, T., Frank, A.: Design, demonstrations and sustainability impact assessments for plug-in hybrid electric vehicles. Elsevier, Renewable and Sustainable Energy Reviews 13, 115-128 (2009)

2. Chan, C., Bouscayrol, A., Chen, K.: Electric, Hybrid, and Fuel-Cell Vehicles: Architectures and Modeling. IEEE Transactions on Vehicular Technology 59, 589-598 (2010)

3. Ferreira, J.C., Silva, A.R., Monteiro, V., Afonso, J.L.: Collaborative Broker for Distributed Energy Resources. In: International Symposium on Computational Intelligence for Engineering Systems, Portugal (2011)

4. Moslehi, K., Kumar, R.: A Reliability Perspective of the Smart Grid. IEEE Transactions on Smart Grid 1, 57-64 (2010)

5. Medina, J., Muller, N., Roytelman, I.: Demand Response and Distribution Grid Operations Opportunities and Challenges. IEEE Transactions on Smart Grid 1, 193-198 (2010)

6. Molderink, A., Bakker, V., Bosman, M., Hurink, J., Smit, G.: Management and Control of Domestic Smart Grid Technology. IEEE Transactions on Smart Grid 1, 109-119 (2010)

7. Khaligh, A., Zhihao, L.: Battery, Ultracapacitor, Fuel Cell, and Hybrid Energy Storage Systems for Electric, Hybrid Electric, Fuel Cell, and Plug-In Hybrid Electric Vehicles: State of the Art. IEEE Transactions on Vehicular Technology 59, 2806-2814 (2010)

8. Monteiro, V., Gonçalves, H., Afonso, J.L.: Impact of Electric Vehicles on Power Quality in a Smart Grid Context. In: 11th IEEE EPQU International Conference on Electrical Power Quality and Utilization, Portugal (2011) 
9. Gomez, J., Morcos, M.: Impact of EV battery chargers on the power quality of distribution systems. IEEE Transactions on Power Delivery 18, 975-981 (2003)

10. Lopes, J., Soares, F., Almeida, P.: Integration of Electric Vehicles in the Electric Power System. Proceedings of the IEEE 99, 168-183 (2011)

11. Han, S., Han, S., Sezaki, K.: Development of an Optimal Vehicle-to-Grid Aggregator for Frequency Regulation. IEEE Transactions on Smart Grid 1, 65-72 (2010)

12. Sortomme, E., El-Sharkawi, M.: Optimal Charging Strategies for Unidirectional Vehicleto-Grid. IEEE Transactions on Smart Grid 2, 131-138 (2011)

13. Zhang, P., Li, F., Bhatt, N.: Next-Generation Monitoring, Analysis, and Control for the Future Smart Control Center. IEEE Transactions on Smart Grid 1, 186-192 (2010)

14. Heydt, G.T.: The Next Generation of Power Distribution Systems. IEEE Transactions on Smart Grid 1, 225-235 (2010)

15. Sauter, T., Lobashov, M.: End-to-End Communication Architecture for Smart Grids. IEEE Transactions on Industrial Electronics 58, 1218-1228 (2011)

16. Yi, P., Iwayemi, A., Zhou, C.: Developing ZigBee Deployment Guideline Under WiFi Interference for Smart Grid Applications. IEEE Transactions on Smart Grid 2, 110-120 (2011)

17. Sortomme, E., Hindi, M., MacPherson, S., Venkata, S.: Coordinated Charging of Plug-In Hybrid Electric Vehicles to Minimize Distribution System Losses. IEEE Transactions on Smart Grid 2, 198-205 (2011)

18. Monteiro, V., Afonso, J.L., Ferreira, J.C.: An Agent Model for the Simulation of Electrical Vehicle Charging Management. In: IEEE CISTI Conference on Information Systems and Technologies, Portugal, pp. 1-4 (2011)

19. Ferreira, J.C., Silva, A.R., Monteiro, V., Afonso, J.L.: Collaborative Broker for Distributed Energy Resources. In: International Symposium on Computational Intelligence for Engineering Systems, ISEC, Portugal (2011)

20. Bilgin, B., Emadi, A., Krishnamurthy, M.: Design considerations for a universal input battery charger circuit for PHEV applications. In: IEEE ISIE International Symposium on Industrial Electronics, pp. 3407-3412 (2010)

21. Monteiro, V., Gonçalves, H., Ferreira, J.C., Afonso, J.L.: Batteries Charging Systems for Electric and Plug-In Hybrid Electric Vehicles. In: Carmo, J.P., Ribeiro, J.E. (eds.) New Advances in Vehicular Technology and Automotive Engineering, 1st edn., pp. 149-168. InTech (2012)

22. Kisacikoglu, M., Ozpineci, B., Tolbert, L.: Examination of a PHEV Bidirectional Charger System for V2G Reactive Power Compensation. In: IEEE APEC Applied Power Electronics Conference and Exposition, pp. 458-465 (2010)

23. Lee, Y.-J., Khaligh, A., Emadi, A.: Advanced Integrated Bidirectional AC/DC and DC/DC Converter for Plug-In Hybrid Electric Vehicles. IEEE Transactions on Vehicular Technology 58, 3970-3980 (2009)

24. Kurohane, K., Senjyu, T., Yona, A., Urasaki, N., Goya, T., Funabashi, T.: A Hybrid Smart AC/DC Power System. IEEE Transactions on Smart Grid 1, 199-204 (2010) 